\title{
D. Speziari, La plume et le pinceau. Nicolas Denisot, poète et artiste de la Renaissance (1515-1559)
}

\section{Michele Mastroianni}

\section{(2) OpenEdition}

1 Journals

\section{Edizione digitale}

URL: http://journals.openedition.org/studifrancesi/9911

DOI: 10.4000/studifrancesi.9911

ISSN: 2421-5856

\section{Editore}

Rosenberg \& Sellier

\section{Edizione cartacea}

Data di pubblicazione: 1 août 2017

Paginazione: 344-345

ISSN: 0039-2944

\section{Notizia bibliografica digitale}

Michele Mastroianni, «D. Speziari, La plume et le pinceau. Nicolas Denisot, poète et artiste de la

Renaissance (1515-1559)», Studi Francesi [Online], 182 (LXI | II) | 2017, online dal 01 août 2017, consultato il 07 janvier 2021. URL: http://journals.openedition.org/studifrancesi/9911 ; DOI: https:// doi.org/10.4000/studifrancesi.9911

Questo documento è stato generato automaticamente il 7 janvier 2021.

\section{(c) $(1) \ominus$}

Studi Francesi è distribuita con Licenza Creative Commons Attribuzione - Non commerciale - Non opere derivate 4.0 Internazionale. 


\title{
D. Speziari, La plume et le pinceau. Nicolas Denisot, poète et artiste de la Renaissance (1515-1559)
}

\author{
Michele Mastroianni
}

\section{NOTIZIA}

DANIELE SPEZIARI, La plume et le pinceau. Nicolas Denisot, poète et artiste de la Renaissance (1515-1559), Genève, Droz, 2016, 288 pp.

1 Giovane e attivissimo studioso del Rinascimento francese, Daniele SPEZIARI fa uscire per le edizioni Droz un denso e ricco volume su una figura importante qual è quella di Nicolas Denisot, anche se per molto tempo trascurata dalla critica, rappresentativa a pieno titolo dell'intellettuale erudito del xvi secolo e dell'uomo politicamente accorto, capace di trarre vantaggio dal potere per fini personali e culturali. In possesso di svariate doti che lo portano alla notorietà, Denisot, ecclettico poeta, disegnatore, editore e precettore, lega il suo nome alla poetica della Pléiade e alla celebre querelle che vede al centro di aspre tensioni dell'epoca due noti autori come Marot e Sagon.

2 La solida monografia di Speziari si compone di sei capitoli, preceduti da una introduzione (pp. 9-15) che inquadra le questioni oggetto delle indagini, ridiscusse e poi confermate nelle conclusioni (pp. 243-248), chiarendo la prospettiva critica seguita, puntualmente in dialogo con le ipotesi avanzate e il bilancio finale prudentemente disegnato. Prospettiva che viene confermata non solo nella conduzione delle analisi e della ricostruzione storiografica e storico-politica cui costantemente sono riportate la vita e l'opera di Denisot, momento indispensabile questo - spiega giustamente Speziari - per la comprensione del ruolo dell'intellettuale nel panorama rinascimentale francese, ma anche nella conduzione complessiva del lavoro che, come annunciato nelle pagine liminari, è centrata sul proseguimento di alcuni studi fondatori (la monografia di Clément Jugé che nel 1969 contribuì a ridare importanza alla figura di 
Denisot e, soprattutto, un importante articolo di Enea Balmas del 1978 che resta una costante imprescindibile delle ricerche di Speziari), ma attraverso una rilettura che per il tramite di nuovi dati di archivio estrapolati da documenti portati all'interesse della critica da Speziari per la prima volta, fanno nuova luce su Nicolas Denisot, permettendo allo specialista in particolare di «apprécier les années d'or de la Pléiade d'un point de vue différent, marginal et central en même temps, et de mieux connaître un moment de l'histoire littéraire de la Renaissance à travers la contribution de celui qui est de nos jours réputé "mineur" mais qui ne l'était assurément pas à son époque: au contraire, sans jamais adhérer au programme prôné par Ronsard (mais en s'y opposant moins nettement qu'on ne l'a cru), il a été au cœur du mouvement de renouvellement des lettres sous le règne d'Henri II et a même rencontré, au moins pendant quelques années, une faveur et une popularité extraordinaires et qui ne manquent pas de nous étonner, avant de connaître la disgrâce et d'être à peu près complètement oublié après sa mort».

3 Il I capitolo («Cheminements d'une existence entre poésie et peinture», pp. 17-85) è strutturato su una fitta serie di dati attraverso cui viene ricostruita la biografia dell'autore, connessa con la sua esperienza pittorica. Connessione che testimonia della complessità dell'opera di questa figura di intellettuale rinascimentale da un lato e della sua evoluzione dall'altro, nel corso del tempo. Nel II capitolo («Des Noelz aux Cantiques: Nicolas Denisot, la tradition 'noelique' et le débat autour de la poésie d'inspiration sacrée», pp. 87-148) sono oggetto di analisi serrate due importanti raccolte poetiche di Denisot: i Noelz (1545) e i Cantiques (1552). Lo studio condotto da Speziari sulla prima raccolta è storicamente contestualizzato in alcune pagine ove sono ripercorsi i momenti fondamentali della nascita e dell'evoluzione dei Noelz, mentre le analisi sulla seconda poggiano sulla discussone critica di talune questioni centrali all'interno dell'elaborazione di una poesia di ispirazione cristiana come quella dei Noelz, questioni che toccano problemi complessi quali in particolare la sovrapposizione di tutta una tradizione antica, teologico-pagana, pregnante, come noto, nel Rinascimento europeo, la quale genera il fenomeno interessantissimo ma delicato del sincretismo paganocristiano del xvi secolo. Questa seconda sezione apre un confronto critico di difficile discussione che Speziari riesce però a condurre con le giuste proporzioni, insistendo su un punto importante. Lo studioso sottolinea infatti che «la différence entre le premier et le deuxième recueil poétique de Denisot est visible dès le titre: Noelz se rattache [...] à un sous-genre établi de caractère populaire, tandis que l'emploi du titre Cantiques est révélateur d'une ambition de plus haute visée. C'est pourquoi, malgré la continuité du sujet, la référence à la tradition 'noélique' ne suffira plus pour comprendre les Cantiques, il faudra les insérer dans un débat plus large autour de la poésie d'inspiration chrétienne». Nel III capitolo («Le Ms. Royal 12 A VII (British Library) ou les Muses anglaises de Nicolas Denisot», pp. 149-165), importante per i dati inediti riportati e discussi, l'A. concentra il discorso sul manoscritto in latino offerto al giovane Edoardo VI, re d'Inghilterra. È questa una sezione dei lavori che ha il pregio di fare luce sulla formazione classica di Denisot, con particolare riferimento alla conoscenza del mondo culturale di espressione latina dell'autore, ma anche alla dimensione più particolareggiata e circoscritta del contesto umanista cui appartiene Denisot, ai suoi rapporti intellettuali, ai legami politici (elogio commemorativo di Enrico VIII, elaborazione dei tombeaux per Margherita di Navarra), alle ascendenze culturali appunto (le fonti) che agiscono in lui, tanto da permetterne - così come Speziari dimostra in tutto il suo lavoro - una lettura attenta alla ricostruzione delle dinamiche 
contestuali dell'epoca, in chiave storico-letteraria. Proprio attraverso lo studio dei tombeaux dedicati a Margherita di Navarra si crea il passaggio fra il III e il IV capitolo («Denisot et l'évolution du tombeau poétique: de l'Hecatodistichon au Tombeau de Marguerite de Valois royne de Navarre», pp. 167-203). Quarto capitolo in cui l'attenzione è rivolta alle analisi comparate delle due opere in questione e ai centoquattro distici latini attribuiti alle tre sorelle Seymour, allieve di Denisot durante il suo soggiorno in Inghilterra e figlie del duca di Sommerset, al tempo governatore del re Edoardo VI. Procedendo così verso la fine della sua monografia, Speziari, nel capitolo V (Nicolas Denisot artiste, pp. 205-220), prima illustra i lavori dell'umanista, questa volta presentato sotto le vesti di cartografo e di autore/ritrattista, poi chiude, con il capitolo VI («Denisot ou pseudo-Denisot? À propos des attributions anciennes et modernes», pp. 221-242), in cui mette in discussione la questione dell'attribuzione di certi scritti, questione controversa relativamente a Nouvelles Récréations et joyeux devis di Bonaventure de Périers e a L'Amant resuscité de la mort d'amour.

Il volume, arricchito da immagini e tabelle molto utili per lo studioso, si impone come studio aggiornato, accurato e scientificamente originale per la disamina e per il materiale inedito che offre (fra cui non va dimenticata la scoperta da parte di Speziari del testamento di Denisot, che ha permesso di ridefinire la biografia dell'autore e la sua collocazione nel contesto storico-culturale della prima metà del xvI secolo). È ora questo un ottimo strumento di ricerca da cui la critica di settore dovrà partire per studi futuri che vogliano ancora indagare la figura composita e complessa di Nicolas Denisot. 